\title{
Investigating the Relationship between the Brittleness Index and Crack Initiation Stress for the Granite under Triaxial Compression
}

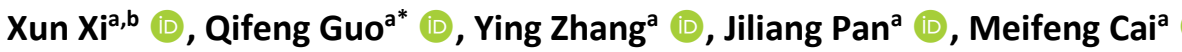 \\ a School of Civil and Resource Engineering, University of Science and Technology Beijing, Beijing, 100083, China. E-mails: \\ xun.xi@strath.ac.uk, guoqifeng@ustb.edu.cn, b20160024@xs.ustb.edu.cn; b20170008@xs.ustb.edu.cn; caimeifeng@ustb.edu.cn \\ b Department of Civil and Environmental Engineering, University of Strathclyde, Glasgow, G1 1XJ, UK. \\ *Corresponding author
}

https://doi.org/10.1590/1679-78255984

\begin{abstract}
The brittle failure of rock is closely related to the rock crack initiation, propagation, coalescences and nucleation. Although many brittleness indexes have been proposed to describe the brittle behavior of rocks, the relationship between the brittleness index and crack initiation stress under triaxial compressive states has not been fully understood. This paper introduced the current main brittleness indexes and discussed their applicabilities for triaxial compressive tests. Granite specimens from a gold mine are prepared for experimental tests. The triaxial compressive tests are carried out on stiff testing machine and the confining pressures are 5 to $110 \mathrm{MPa}$. Experimental results on the stress-strain curves show that the post-peak behaviors of the granite under confining pressures are in Class I and Class II types. The brittleness indexes, crack initiation stress, compressive strength, elastic moduls and Poisson's ratio of the granite are obtained and discussed. It has been found that, the crack initiation stress linearly increases with the increasing of confining pressure. Moreover, a power function can describe the relationship between the brittleness index and crack initiation stress for Class I rock behavior while an exponential function can describe the relationship between the brittleness index and crack initiation stress for Class II rock behavior.
\end{abstract}

\section{Keywords}

Brittleness index, Crack Initiation Stress, Granite; Confining pressure; Triaxial compression.

\section{Graphical Abstract}

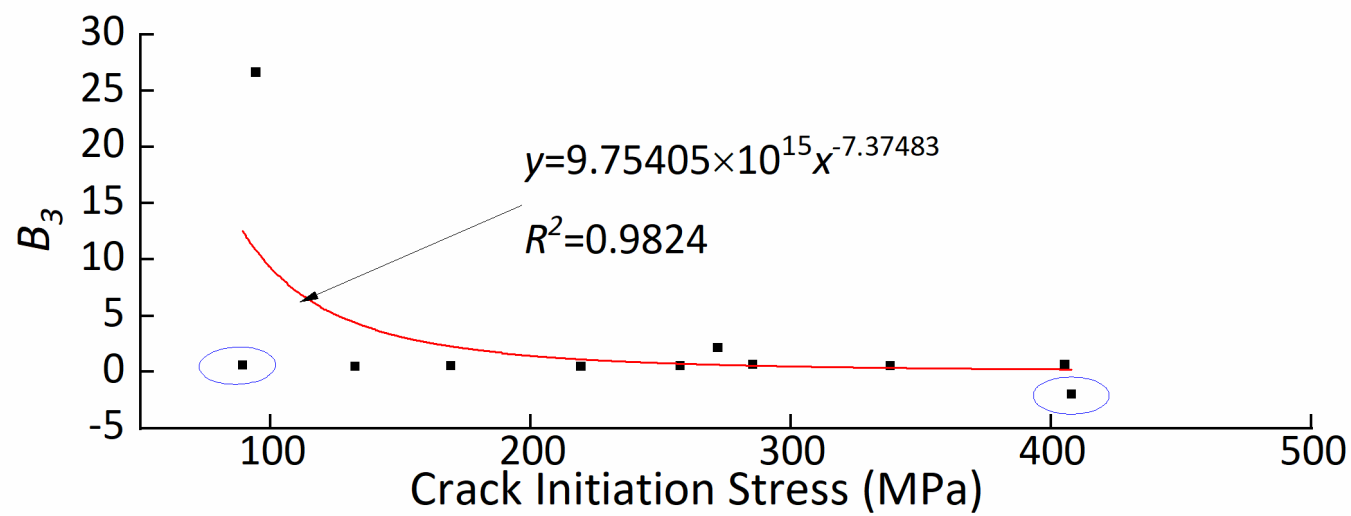




\section{INTRODUCTION}

Evaluation of rock mechanical properties, especially fracture properties, is essential to the design and management of rock engineering such as slopes, tunnels and cavens. Besides the very fundamental mechanical parameters (i.e., elastic modulus, strength, fracture toughness, etc.), extensive researches have been carried out to propose new parameters or indexes to quantitatively evaluate rock fracture properties and predict rock mechanical behaviors (Tarasov and Potvin, 2013; Wawersik and Fairhurst, 1970; Batougina et al., 1983; Ashby and Sammis, 1990; Stavrogin and Protossenia, 1985; Baron, 1992; Aubertin et al., 1994; Xia, et al., 2016; Bishop,1967; Hajiabdolmajid, et al., 2002; Hajiabdolmajid and Kaiser, 2003; Li et al., 2012). Amongst the parameters, brittleness index (BI) has been widely employed to predict rock burst potential and develop unconventional reservoirs (Tarasov and Potvin, 2013; Mews et al., 2019). The brittle failure of rock is closely related to the crack initiation, propagation, coalescences and nucleation from micro to macro scales (Damjanac and Fairhurst, 2010; Xi et al., 2018a, 2018b; Guo et al., 2020; Xi et al., 2020). Further, as a necessary precursor to rock brittle failure, crack initiation stress (CIS) has been a key parameter for the prediction of rock fracture (Cai et al., 2004). Therefore, modelling the relationship between crack initiation stress and brittleness index will enhance the understanding of rock fracture properties.

To date, many different expressions for the brittleness index have been proposed based on the mineral composites, microstructures, penetration, energy balance analysis, unconfined compressive strength and/or Brazilian tensile strength, etc (Mews et al., 2019). Coates and Parsons (1966) proposed to use the ratio of the reversible strain to the total strain at the point of failure for the brittleness index. Hucka and Das (1974) used the difference between the compressive and the tensile strengths to express the brittleness of friable substances like coal. Aubertin et al (1994) proposed a brittleness index by using the ratio between the recoverable elastic strain energy of peak strength and the total energy. Hajiabdolmajid and Kaiser (2003) considered the rock brittle failure as a time- and size-dependent process and proposed a train-dependent brittleness index. However, rock behaviors are classified into Class I or Class II based on the characteristic shape of their post-peak curve (Akinbinu, 2016). The brittleness index should consider the difference between Class I and Class II behaviors (Tarasov and Potvin, 2013) Rybacki et al. (2016) proposed to use the mineral composites and percentage to predict the brittleness of shale. It has been found that, there is no unified form of rock brittleness and no generally applicable brittleness index for different rocks. Moreover, most researches on brittleness analyses were based on uniaxial tests.

Since Sih (1974) used a strain energy density factor based on Griffith theory to predict the crack initiation and direction of rock, considerable researches have been carried out on rock fracture (Bažant et al., 1993; Cai et al., 2004; Diederichs et al., 2004; Xu et al., 2018; Guo et al., 2020). Bažant et al. (1993) derived a simple size effect law which directly related to the fracture properties of rock. Cai et al. (2004) discussed the crack initiation stress of rock from experimental data and found that crack initiation normally occurred at 0.3 to 0.5 times the peak uniaxial compressive stress. Xu et al. (2018) collected the experimental data for crack initiation stress and tensile strength of rocks and found that the crack initiation stress had a linear relationship with Brazilian tensile strength. Jiang et al. (2020) collected uniaxial compression test data for igneous, metamorphic, and sedimentary rocks and found that the brittleness index can be expressed as a 2-parameter power function of CIS ratio (i.e., the ratio of crack initiation ratio to uniaxial compression strength). However, natural rock is normally in a triaxial stress state and the confining pressure significantly affects the rock mechanical behaviors (Akinbinu, 2016). The relationship between brittleness and crack initiation of granite based on triaxial compressive tests has never been fully understood.

This paper firstly reviewed some existing expressions for brittleness index and discussed the applicabilities of the brittleness indexes for the granite under triaxial compressive tests. Granite samples taken from a deep mine are used for traixial compressive tests. The experimental confining pressure are $5 \mathrm{MPa}, 10 \mathrm{MPa}, 20 \mathrm{MPa}, 30 \mathrm{MPa}, 40 \mathrm{MPa}, 50 \mathrm{MPa}$, $60 \mathrm{MPa}, 70 \mathrm{MPa}, 80 \mathrm{MPa}, 90 \mathrm{MPa}, 100 \mathrm{MPa}$ and $110 \mathrm{MPa}$. The stress-strain curves for the different confining pressures are obtained. The crack initiation stresses and the brittleness indexes in four different expressions are calculated based on the experimental data. The crack angles between the main crack and loading axial for different confining pressures are measured. Further, the relationships between the crack initiation stress and confining pressure, elastic modulus and possion's ratios are analyzed. Finally, regression analyses and discussions on the relationship between the crack initiation stress and brittle indexes are carried out.

\section{Existing expressions for brittleness index}

The stress-strain curve is the most important description for the deformation and failure of rock under external loads. Therefore, most popular brittleness indexes were based on the stress-strain curve of rock (Tarasov and Potvin, 2013; Wawersik and Fairhurst, 1970; Batougina, et al., 1983; Bažant, 1993; Stavrogin and Protossenia, 1985; Baron, 1992; 
Aubertin, et al., 1994; Xia, et al., 2016; Bishop,1967; Hajiabdolmajid, et al., 2002; Hajiabdolmajid and Kaiser, 2003; $\mathrm{Li}$, et al., 2012). Further, the determination for the brittle indexes can be divided into the curve energy method and curve shape method. In this paper, the brittleness indexes based on the curve energy are $B_{1}-B_{6}$, and the brittleness indexes based on the curve shape method are $B_{7}-B_{10}$.

As shown in Figure 1, Tarasov and Potvin (2013) considered the difference between Class I and Class II stress-strain curves of rock for calculating the brittleness indexes which can be expressed as follows:

$B_{1}=\frac{\mathrm{d} W_{\mathrm{r}}}{\mathrm{d} W_{\mathrm{e}}}=\frac{M-E}{M}$

$B_{2}=\frac{\mathrm{d} W_{\alpha}}{\mathrm{d} W_{\mathrm{e}}}=\frac{E}{M}$

where $E$ is the elastic modulus before the peak; $M$ is the post-peak modulus. For the Class I behavior of rock, the value of $M$ is negative. For the class II of behavior. the value of $M$ is positive. It should be mentioned that, the $E$ should be calculated by the unloading tangent line at the peak load point but can be simplified as the loading modulus at the elastic stage. The $M$ can be determined on the basis of a tangent line after the peak.
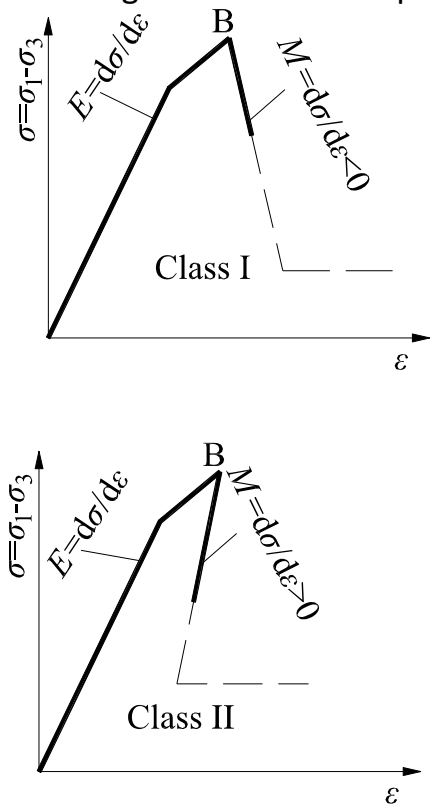

Figure 1 The schematic diagram of brittleness indexes $B_{1}$ and $B_{2}$

Batougina et al (1983) and Stavrogin and Protossenia (1985) proposed the brittleness indexes of $B_{3}$ and $B_{4}$ which are similar to $B_{1}$ and $B_{2}$.

$B_{3}=\frac{M}{E+M}$

$B_{4}=\frac{M}{E}$

Baron (1992) and Aubertin et al (1994) proposed the brittleness index of $B_{5}$ by using the ratio between the recoverable elastic strain energy of peak strength on the stress-strain curve and the total energy.

$B_{5}=A_{2} / A_{1}$ 
where $A_{2}$ is the recoverable elastic strain energy at the peak strength (i.e., the area of $B C D$ in Figure 2 ), and $A_{1}$ is the total energy at the peak strength (i.e., the area of OABD in Figure 2).

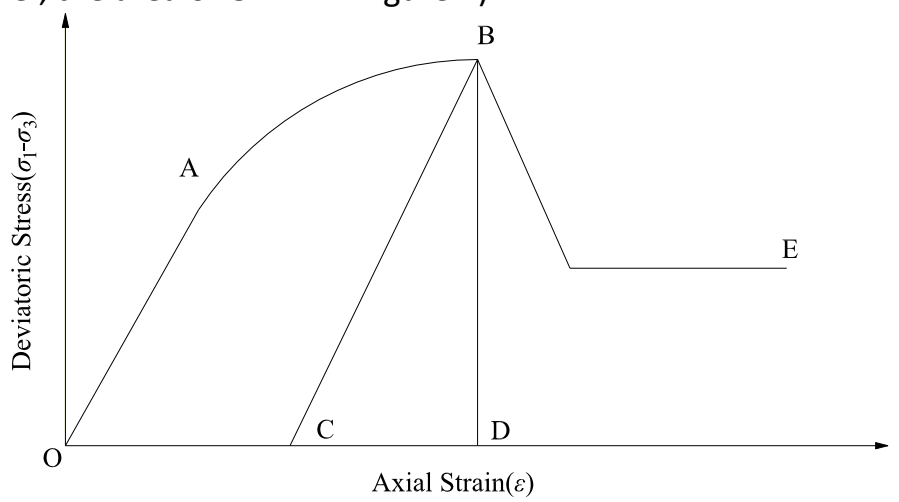

Figure 2 The schematic diagram of brittleness index $B_{5}$

Xia et al (2016) thought that brittleness of rock was dependent on the ratio of stress drop vs strain increasing after the peak. Therefore, they proposed the brittleness index of $B_{6}$ which can be expressed as follows:

$B_{6}=\left(\sigma_{\mathrm{p}}-\sigma_{\mathrm{r}}\right) /\left(\varepsilon_{\mathrm{r}}-\varepsilon_{\mathrm{p}}\right)+\left[\left(\sigma_{\mathrm{p}}-\sigma_{\mathrm{r}}\right)\left(\varepsilon_{\mathrm{r}}-\varepsilon_{\mathrm{p}}\right)\right] /\left(\sigma_{\mathrm{p}} \varepsilon_{\mathrm{p}}\right)$

where $\sigma_{\mathrm{p}}$ is the peak strength, $\sigma_{\mathrm{r}}$ is the residual strength, $\varepsilon_{\mathrm{p}}$ is the peak strain and $\varepsilon_{\mathrm{r}}$ is the residual strain.

Bishop (1967) believed that the brittleness of rock can be described by a function of peak strength and residual strength and the larger the difference between the peak strength and residual stress is, the stronger the brittleness is. The brittleness index of $B_{7}$. is expressed as follows:

$B_{7}=\left(\sigma_{\mathrm{p}}-\sigma_{\mathrm{r}}\right) / \sigma_{\mathrm{p}}$

where $\sigma_{\mathrm{p}}$ is the peak strength, $\sigma_{\mathrm{r}}$ is the residual strength.

Hajiabdolmajid et al. $(2002,2003)$ regarded the brittleness of rock as strain-dependent index and proposed the brittleness index of $B_{8}$ based on the peak strain and residual strain as follows:

$B_{8}=\left(\varepsilon_{\mathrm{p}}-\varepsilon_{\mathrm{r}}\right) / \varepsilon_{\mathrm{p}}$

where $\varepsilon_{\mathrm{p}}$ is the peak strain, and $\varepsilon_{\mathrm{r}}$ is the residual strain.

$\mathrm{Li}$ et al (2012) proposed the brittleness index of $B_{9}$ in consideration of strain and the shape parameters of the stressstrain curve.

$$
\begin{aligned}
& B_{9}=\left(\varepsilon_{\text {BRIT }}-\varepsilon_{\mathrm{n}}\right) /\left(\varepsilon_{\mathrm{m}}-\varepsilon_{\mathrm{n}}\right)+\alpha C S_{\text {BRIT }}+\beta C S_{\text {BRIT }}+\eta \\
& C S_{\text {BRIT }}=\left[\varepsilon_{\mathrm{p}}\left(\sigma_{\mathrm{p}}-\sigma_{\mathrm{r}}\right)\right] /\left[\sigma_{\mathrm{p}}\left(\varepsilon_{\mathrm{r}}-\varepsilon_{\mathrm{p}}\right)\right]
\end{aligned}
$$

where $\varepsilon_{\mathrm{BRIT}}$ is the parameter of peak strain; $\varepsilon_{\mathrm{m}}$ and $\varepsilon_{\mathrm{n}}$ are the reference values of the maximum peak strain and the minimum peak strain, respectively. $C S_{\text {BRIT }}$ is the parameter of curve shape after the peak, while $\alpha, b$ and $\eta$ are the standardization coefficients.

Chen et al (2018) introduced the crack initiation stress into the brittleness index.

$B_{10}=\left[\left(\sigma_{\mathrm{p}}-\sigma_{\mathrm{ci}}\right) / \sigma_{\mathrm{p}}\right] /\left[\left(\varepsilon_{\mathrm{p}}-\varepsilon_{\mathrm{ci}}\right) / \varepsilon_{\mathrm{p}}\right]+\left[\left(\sigma_{\mathrm{p}}-\sigma_{\mathrm{r}}\right) / \sigma_{\mathrm{p}}\right] /\left[\left(\varepsilon_{\mathrm{r}}-\varepsilon_{\mathrm{p}}\right) / \varepsilon_{\mathrm{p}}\right]$

where $\sigma_{\mathrm{ci}}$ is the crack initiation stress. 
Amongst the above ten brittleness indexes, only $B_{1}-B_{4}$ considered the Class I and Class II behaviors of rocks. Moreover, Class II behavior of rock is very likely to occur for triaxial compressive tests with high confining pressures and very stiff testing machines (Akinbinu, 2016). Thus, this paper focuses to study the relationship between the crack initiation stress and the brittleness indexes of $B_{1}-B_{4}$.

\section{Selection of Samples and determination of crack initiation stresses}

Granite is regarded as a typical brittle rock and the outburst failure of granite in the high-stress state has been a huge threat to deep mines (Cai and Brown, 2017). Therefore, we took granite from a deep gold mine where the mining depth has exceeded $-1000 \mathrm{~m}$. The average density of granite is $2624.23 \mathrm{~kg} / \mathrm{m}^{3}$, and the average longitudinal wave velocity is $4.95 \mathrm{~km} / \mathrm{s}$. The average porosity of the granite specimen is $1.42 \%$. Figure 3 shows the mineral compositions of the granite under the microscope. The main mineral compositions are plagioclase (PI), K-feldspar (Kfs), quartz (Qtz) and biotite (Bt). The samples are carefully taken for avoiding the microcracks existing and then made as cylinders with standard dimensions of $50 \mathrm{~mm}$ in diameter and $100 \mathrm{~mm}$ in height. A stiff testing machine with high confining pressure configuration (MTS815) in University of Minnesota (Figure 4) is employed to carry out the triaxial compression tests. The confining pressures are 5, 10, 20,30,40,50,60,70,80, 90, 100 and $110 \mathrm{MPa}$, respectively. The loading rate is $0.0005 \mathrm{~mm} / \mathrm{s}$ and the control of circumferential extensometer is adopted for the test.

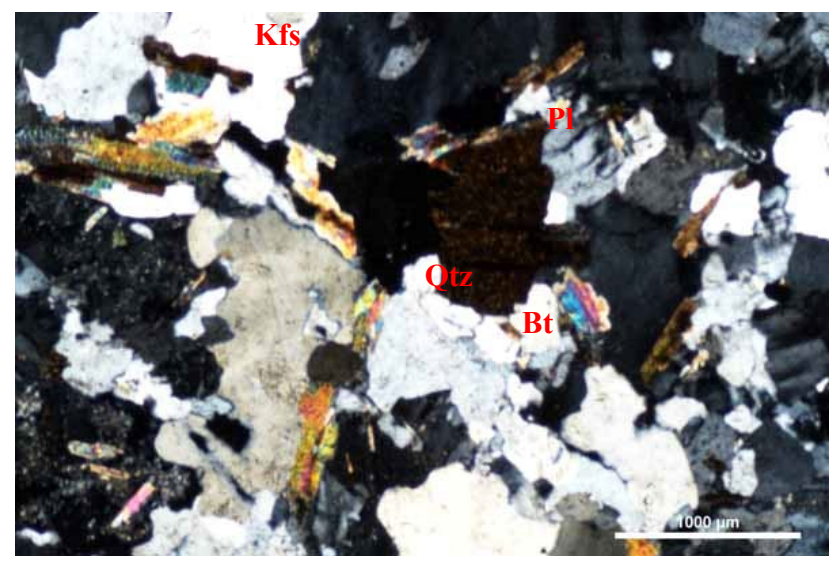

Figure 3 The mineral compositions of Sanshandao granite under the microscope

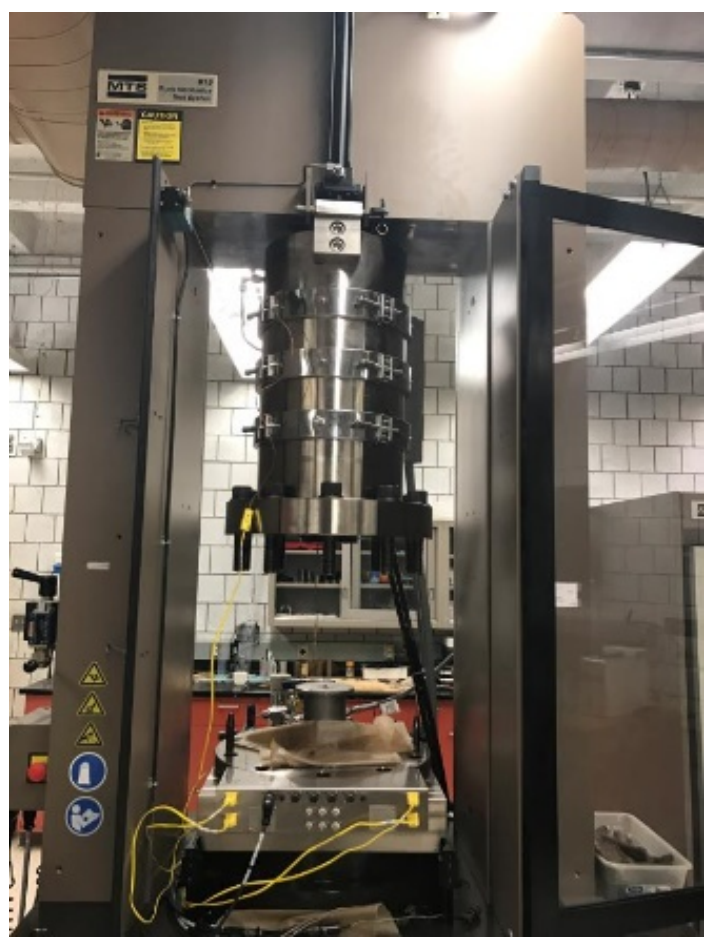

Figure 4 MTS815 testing machine 
Table 1 Summary for the determination methods of the crack initiation stress

\begin{tabular}{|c|c|c|}
\hline Methods & Advantages & Disadvantages \\
\hline $\begin{array}{l}\text { Volumetric Strain } \\
\text { Method }\end{array}$ & $\begin{array}{l}\text { It is relatively intuitional and simply by adopting the variation } \\
\text { of volumetric strain to determine the crack initiation stress of } \\
\text { rock. }\end{array}$ & $\begin{array}{l}\text { The volumetric strain method depends on the } \\
\text { tangent line made by manual work to determine } \\
\text { the crack initiation stress, so that the subjectivity } \\
\text { and error of value cannot be avoided. }\end{array}$ \\
\hline $\begin{array}{l}\text { Lateral Strain } \\
\text { Method }\end{array}$ & $\begin{array}{l}\text { It is an improvement of volumetric strain method, and has the } \\
\text { advantages of volumetric strain method. Compared to the } \\
\text { volumetric strain method, this method eliminates the } \\
\text { influence of axial strain, and the interference factors of } \\
\text { determining the crack initiation stress are few. }\end{array}$ & $\begin{array}{c}\text { The difficulty of accurate value is increased once } \\
\text { the lateral strain curve appears a prominent } \\
\text { non-linear feature. }\end{array}$ \\
\hline $\begin{array}{l}\text { Crack Volumetric } \\
\text { Strain Method }\end{array}$ & $\begin{array}{l}\text { Compared to the volumetric strain method and lateral strain } \\
\text { method, this method does not adopt the tangent line made by } \\
\text { manual work to determine the crack initiation stress. } \\
\text { Therefore, the obtained value of the crack initiation stress is } \\
\text { comparatively objective. Meanwhile, it avoids depending on } \\
\text { the selection for closing point of fracture during the } \\
\text { determination of the crack initiation stress. }\end{array}$ & $\begin{array}{l}\text { This method depends on the calculations of } \\
\text { elasticity modulus and Poisson's ratio. It is more } \\
\text { sensitive to the variation of Poisson's ratio. In } \\
\text { addition, a certain error will be easily caused for } \\
\text { the judgment on that the crack initiation point is } \\
\text { deviated from the zero point. }\end{array}$ \\
\hline $\begin{array}{c}\text { Lateral Strain } \\
\text { Response Method }\end{array}$ & $\begin{array}{l}\text { It has the uniqueness for the extreme value worked out by } \\
\text { using this method thought the reliable mathematical method, } \\
\text { avoids the personal error, and ensure the objectivity of the } \\
\text { crack initiation stress value. }\end{array}$ & $\begin{array}{l}\text { This method is mostly applied to the hard rock, } \\
\text { and has the limited generalization performance. }\end{array}$ \\
\hline AE Method & $\begin{array}{l}\text { As one kind of physical acoustics detection method, it is an } \\
\text { important supplement of normal strain methods by adopting } \\
\text { the acoustic emission technology to explore the fracture } \\
\text { characteristic of rock. }\end{array}$ & $\begin{array}{l}\text { A stronger fluctuation of acoustic emission signal } \\
\text { may be appeared in the fracture close and linear } \\
\text { elasticity stages of rock, and disturbs the accurate } \\
\text { recognition of the crack initiation stress. }\end{array}$ \\
\hline $\begin{array}{c}\text { Numerical } \\
\text { Simulation Method }\end{array}$ & $\begin{array}{l}\text { In order to avoid any personal error, conveniently and rapidly } \\
\text { determine the crack initiation stress through the simulation. }\end{array}$ & $\begin{array}{l}\text { The simulated result needs to be verification } \\
\text { through a test. }\end{array}$ \\
\hline
\end{tabular}

The determination methods for crack initiation stress are mainly based on the measured strain, such as volumetric strain method (Brace, et al., 1966), lateral strain method (Lajtai, 1974), crack volumetric strain method (Martin and Chandler, 1994) and lateral strain response method (Nicksiar and Martin, 2012). And acoustic emission method (Zhao, et al., 2013) and numerical simulation method (Huang and Li, 2017) were also developed. The advantages and disadvantages of the determination methods for crack initiation stress are listed in Table 1 (Cai et al., 2004). The lateral strain response method which is suitable for brittle rock is used for determination the crack initiation stress of the Sanshandao deep granite.

Taking the specimen under the confining pressure of $20 \mathrm{MPa}$ as an example, the steps for determination of the crack initiation stress are as follows: First, as shown in Figure 5(a), the crack damage stress is determined by the turning point of volumetric strain from increasing to decreasing. Then, the corresponding lateral strain to the crack damage stress is obtained and an auxiliary line connecting the point for damaged lateral strain and original point is drawn. Finally, the difference between the auxiliary line and later strain curve as a function of deviatoric stress is obtained as Figure $5(b)$. The stress to the peak of the curve is just the determined crack initiation stress (Cai et al., 2004). The crack initiation stresses for the specimens under different confining pressures will be given later.

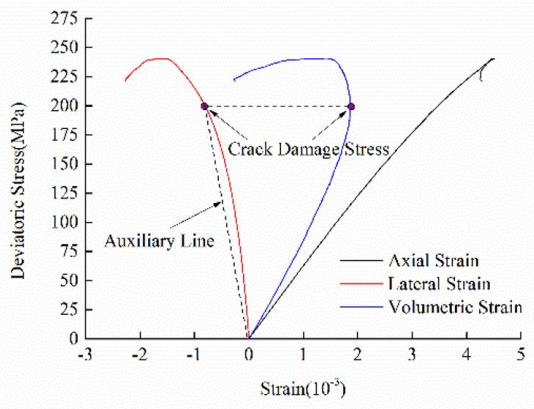

(a)

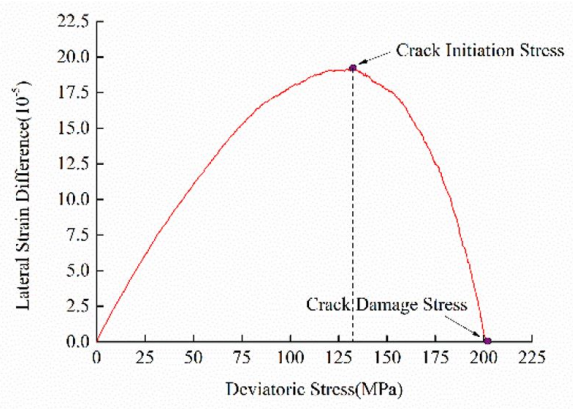

(b)

Figure 5 An example for determination of the crack initiation stress under the confining pressure of 20 MPa: (a) Stress-strains curves; (b) The lateral strain difference curve 


\section{Mechanical Behavior of Specimens under Different Confining Pressures}

The ductility of rocks before the peak will be increased with the increase of confining pressure. However, after the peak, two kinds of rock behaviors (Class I and Class II) can be appeared under the action of confining pressure (Tarasov and Potvin, 2013). Figure 6 illustrates the stress-strain curves of the granite for the different confining pressures. The values of the post-peak modulus are determined by the tangent lines (blue lines for Class I and red lines for Class II). The classification of rock behaviors for different confining pressures is given in Table 2. It can be seen that most post-peak behaviors from the experiments are in Class II for triaxial compressive tests. Therefore, it is necessary to consider the Class II case for the expressions of brittleness indexes. Figure 7 shows the crack patterns of the specimens for different confining pressures. It can be seen that, the failure of the granite under triaxial compressive tests is shear failure with a dominated macro crack which also proves that the failure of granite is brittle fracture failure but not plastic damage. The crack angles between the macro shear crack and axial loading direction are obtained and listed in Table 3 . It can be found that, the crack angle increases from $7^{\circ}$ to $38^{\circ}$ with the confining pressure increasing from $5 \mathrm{MPa}$ to $50 \mathrm{MPa}$. While when the confining pressure is larger than $50 \mathrm{MPa}$, the crack angle generally keeps around $30^{\circ}$. The crack initiation stresses for different confining pressures are also given in Table 3. It can be found that, the crack initiation stress monotonically increases from 89.4 MPa to 426.8 MPa with the confining pressure increasing $5 \mathrm{MPa}$ to $110 \mathrm{MPa}$.
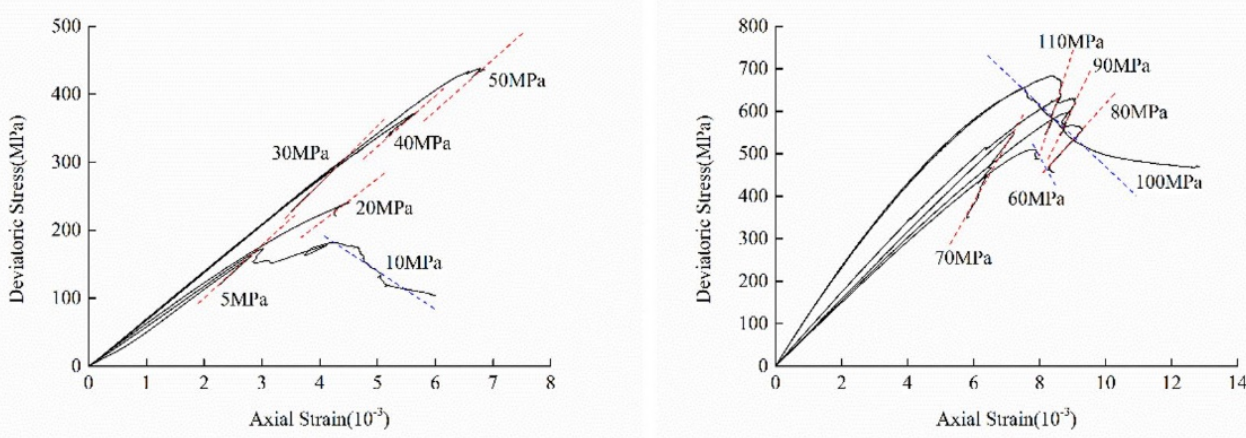

Figure 6 The stress-strain curves of granite under the different confining pressures

Table 2 The post-peak rock behaviors for the different confining pressures

\begin{tabular}{ccccccccccccc}
\hline Confining pressure (MPa) & 5 & 10 & 20 & 30 & 40 & 50 & 60 & 70 & 80 & 90 & 100 & 110 \\
\hline Post-peak behavior (Class) & II & I & II & II & II & II & I & II & II & II & I & II \\
\hline
\end{tabular}
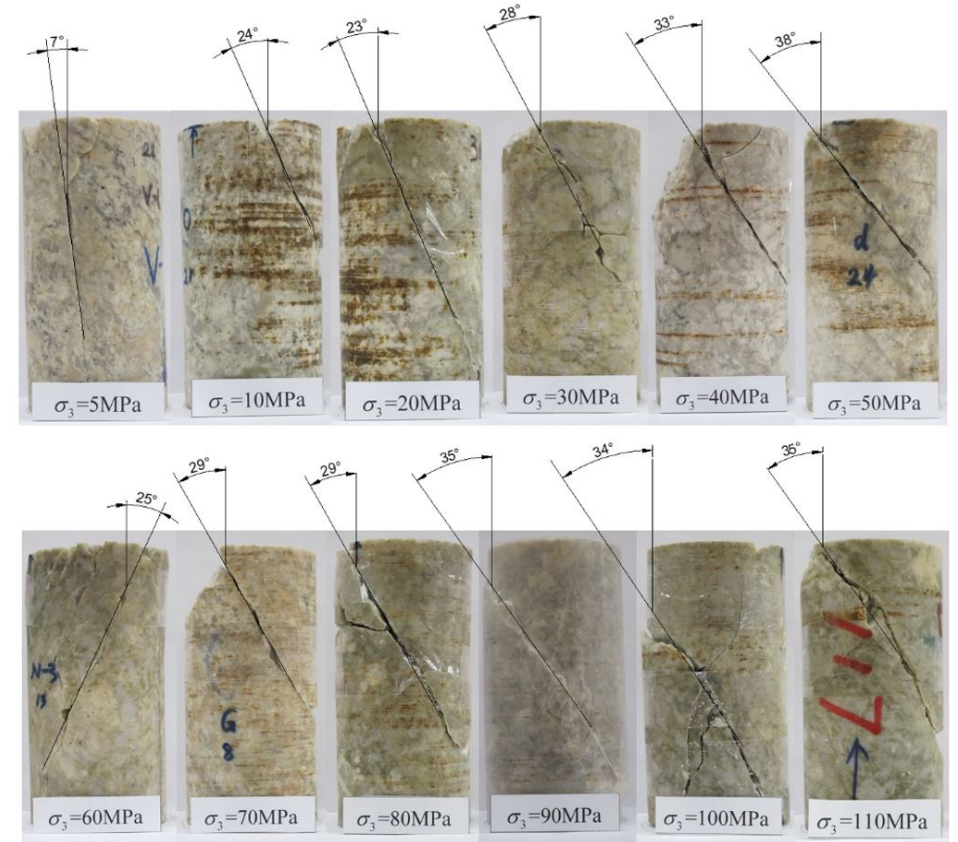

Figure 7 The test results of granite specimens under the different confining pressures 
Table 3 The post-peak rock behaviors for the different confining pressures

\begin{tabular}{|c|c|c|c|c|c|c|c|c|c|c|c|c|}
\hline Confining pressure ( $\mathrm{MPa})$ & 5 & 10 & 20 & 30 & 40 & 50 & 60 & 70 & 80 & 90 & 100 & 110 \\
\hline Crack angle $\left({ }^{\circ}\right)$ & 7 & 24 & 23 & 28 & 33 & 38 & 25 & 29 & 29 & 35 & 34 & 35 \\
\hline Crack Initiation Stress (MPa) & 89.4 & 94.4 & 132.7 & 169.4 & 219.5 & 257.6 & 271.9 & 285.5 & 338.2 & 405.4 & 407.9 & 426.8 \\
\hline
\end{tabular}

Figure 8 illustrates the relationship between the crack initiation stress and confining pressure, Poisson's ratio and elastic modulus. It can be seen that, the crack initiation stress has a linear relationship with the increasing of the confining pressure with the coefficient of determination $R^{2}$ larger than 0.98 . Therefore, the influence of confining pressure significantly affects the crack initiation stress. However, the crack initiation stress has less relevant with the Poisson's ratio. The crack initiation stress generally linearly increases with the increasing of elastic modulus. Since the crack initiation stress is dependent on the confining pressure, it is necessary to consider the relationship between brittleness index and crack initiation stress under triaxial compressive tests.

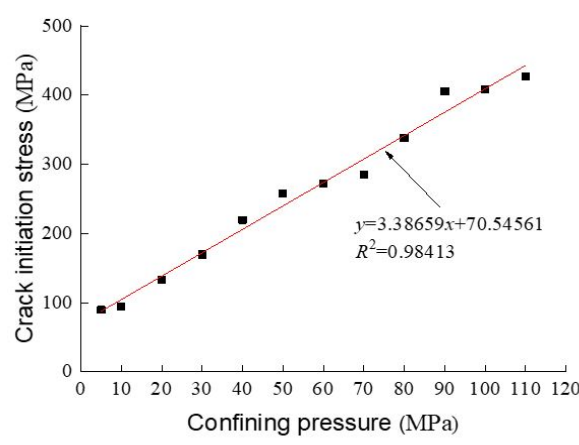

(a)

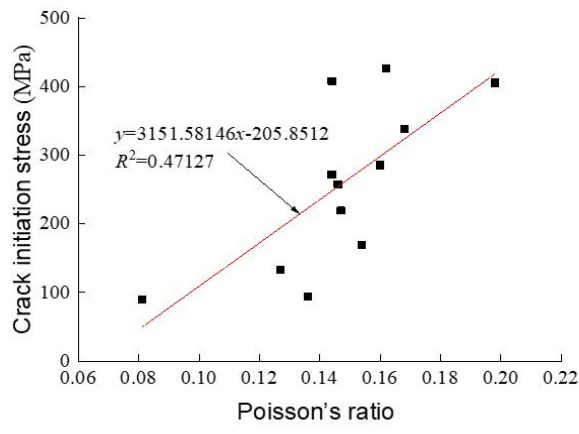

(b)

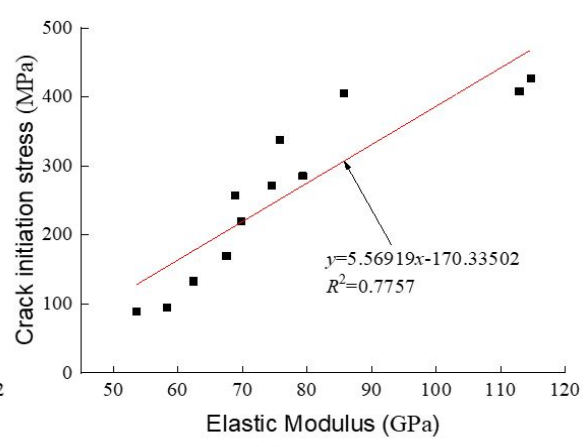

(c)

Figure 8 The relationship between crack initiation stress and (a) confining pressure; (b) Poisson's ratio; and (c) elastic modulus

\section{Regression Analyses Between the Brittleness Index and Crack Initiation Stress}

Table 2 shows the values for the brittleness index $\left(B_{1}, B_{2}, B_{3}\right.$ and $\left.B_{4}\right)$, compressive strength and the ratio of crack initiation stress (i.e., stress ratio) to compressive strength from the experiments. The developments of the compressive strength, the stress ratio and brittleness indexes with the confining pressure increasing are shown as Figure 9 . It can be found that, with the increasing of confining pressure, the compressive strength gradually increases from $159.829 \mathrm{MPa}$ to $670.338 \mathrm{MPa}$. The ratio of crack initiation stress to compressive strength varies from 0.545 to 0.681 . However, there almost no regularity between the confining pressure and the stress ratio. The brittleness index of $B_{1}, B_{2}, B_{3}$ and $B_{4}$ are in the range of 0.021 to $2.496,-1.496$ to $0.979,-2.014$ to 26.624 , and -1.860 to 2.229 , respectively. Moreover, the relationship between brittleness indexes and confining pressure is also not clear.

Table 2 The summary of granite's mechanical parameters

\begin{tabular}{|c|c|c|c|c|c|c|}
\hline \multirow{2}{*}{ Confining Pressure } & \multirow{2}{*}{$\sigma_{\mathrm{c}} / \mathrm{MPa}$} & \multirow{2}{*}{$\sigma_{\mathrm{ci}} / \sigma_{\mathrm{c}}$} & \multicolumn{4}{|c|}{ Brittleness Index } \\
\hline & & & $B_{1}$ & $B_{2}$ & $B_{3}$ & $B_{4}$ \\
\hline 5 & 159.829 & 0.559 & 0.280 & 0.720 & 0.582 & 1.390 \\
\hline 10 & 173.156 & 0.545 & 1.962 & -0.962 & 26.624 & -1.039 \\
\hline 20 & 201.026 & 0.660 & 0.051 & 0.949 & 0.513 & 1.054 \\
\hline 30 & 304.502 & 0.556 & 0.155 & 0.845 & 0.542 & 1.184 \\
\hline 40 & 355.666 & 0.617 & 0.021 & 0.979 & 0.505 & 1.022 \\
\hline 50 & 409.776 & 0.629 & 0.084 & 0.916 & 0.522 & 1.092 \\
\hline 60 & 494.695 & 0.550 & 1.538 & -0.538 & 2.162 & -1.860 \\
\hline 70 & 551.297 & 0.518 & 0.434 & 0.566 & 0.639 & 1.767 \\
\hline 80 & 573.322 & 0.590 & 0.089 & 0.911 & 0.523 & 1.097 \\
\hline 90 & 595.312 & 0.681 & 0.519 & 0.481 & 0.675 & 2.081 \\
\hline 100 & 638.780 & 0.639 & 2.496 & -1.496 & -2.014 & -0.668 \\
\hline 110 & 670.338 & 0.637 & 0.551 & 0.449 & 0.690 & 2.229 \\
\hline
\end{tabular}




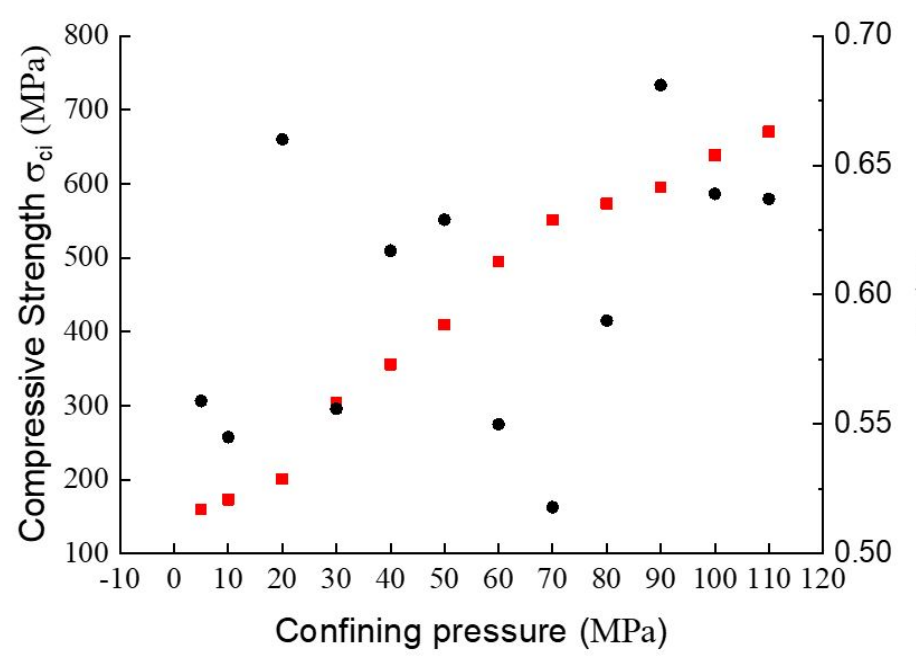

(a)

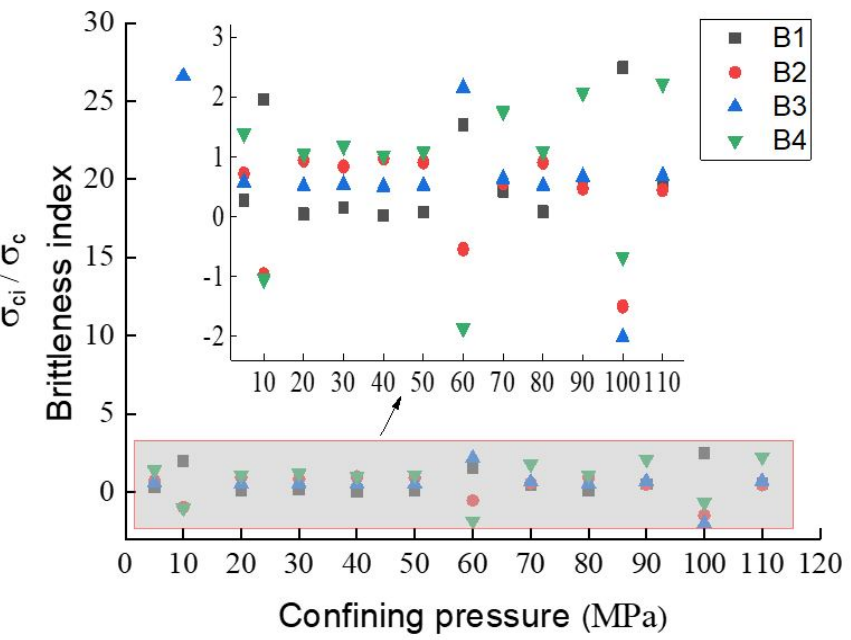

(b)

Figure 9 Strength and brittleness indexes developments with the confining pressure increasing (a) Compressive strength and stress ratio development; (b) Brittleness indexes development

Further, we attempt to establish the relationship between the brittleness indexes and crack initiation stress by multiple function regressions. The exponential function, logarithmic function, power function and polynomial function are used to describe their relationships. Figure 10 illustrates the regressions of brittleness indexes $B_{1}$, $B_{2}, B_{3}$ and $B_{4}$ and crack initiation stress, respectively. It should be mentioned that, unreasonable data points in the blue circle have been removed in the fitting. It can be found that the power function is suitable for the relationship between the crack initiation stress and the brittleness index of $B_{1}$ or $B_{3}$. While the exponential function is suitable for the relationship between the crack initiation stress and the brittleness index of $B_{2}$ or $B_{4}$. The correlation coefficients from the fitting of the brittleness indexes $B_{1}, B_{2}, B_{3}$ and $B_{4}$ are $0.69038,0.80034$ and 0.9824 and 0.72214 . It is interesting to find that, a power function can describe the relationship between the brittleness index and crack initiation stress for Class I rock behavior while an exponential function can describe the brittleness index and crack initiation stress for Class II rock behavior. Further, the brittleness indexes of $B_{1}$, $B_{2}, B_{3}$ and $B_{4}$ can be redefined as:

$B_{1}=\frac{M-E}{M}=a_{1} x^{b_{1}}$

$B_{2}=\frac{E}{M}=a_{2}-b_{2} c_{2}^{x}$

$B_{3}=\frac{M}{E+M}=a_{3} x^{b_{3}}$

$B_{4}=\frac{M}{E}=a_{4}-b_{4} c_{4}^{x}$

where $x$ is the crack initiation stress, namely that $x=\sigma_{\text {ci. }} a_{1}, a_{2}, a_{3}, a_{4}, b_{1}, b_{2}, b_{3}, b_{4}, c_{2}$ and $c_{4}$ are all the fitting constants. 


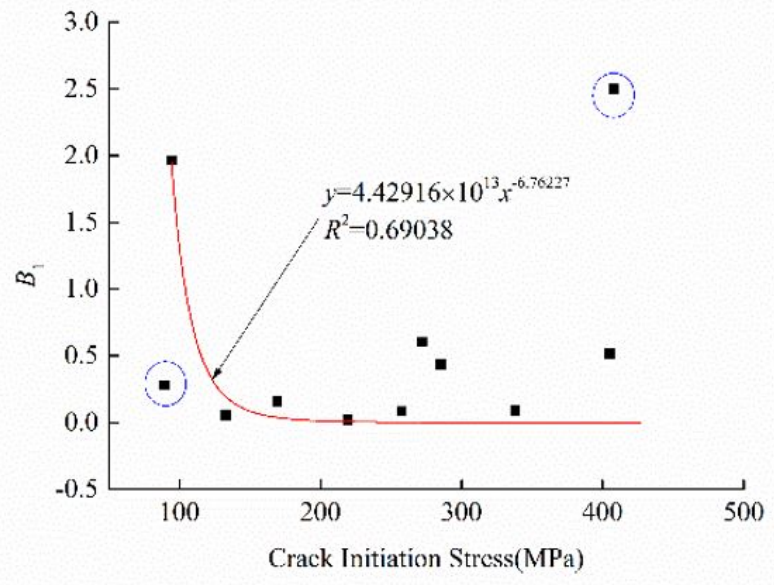

(a)

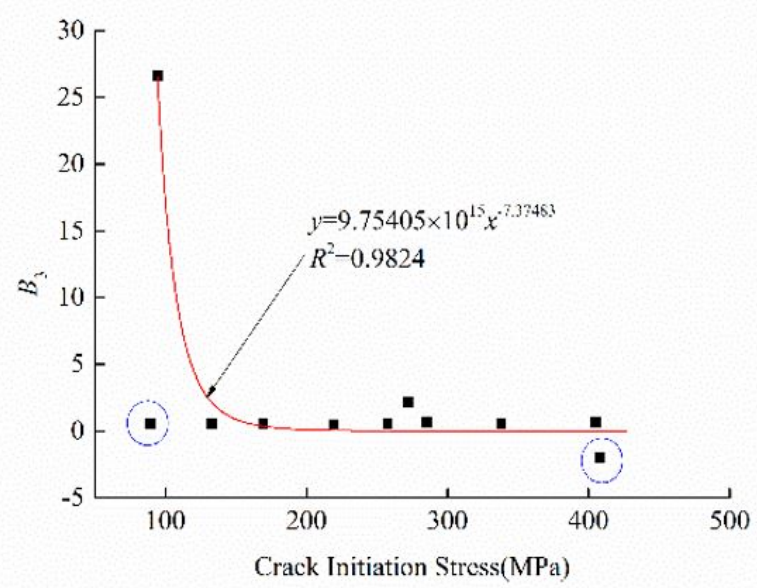

(c)

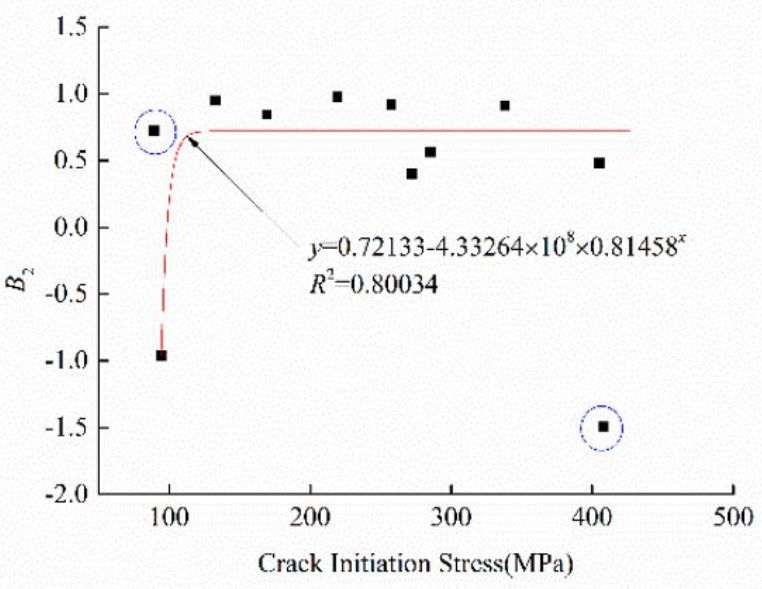

(b)

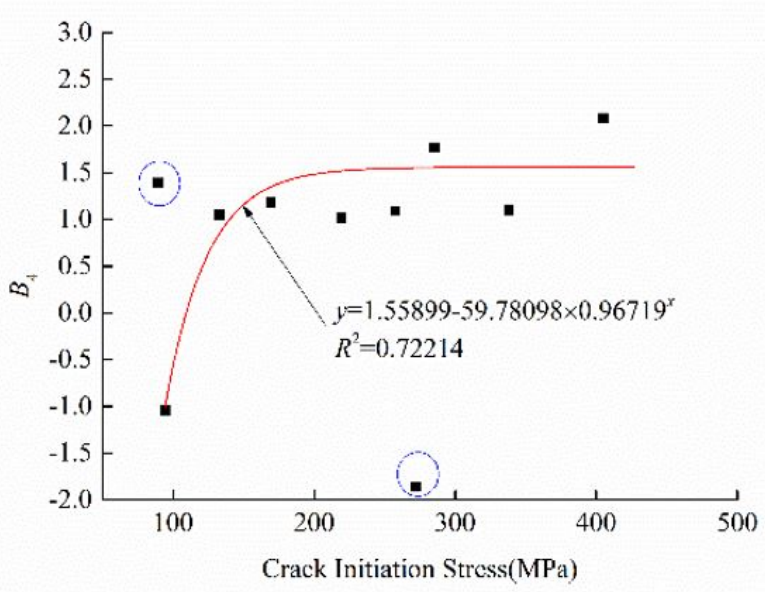

(d)

Figure 10 The relationship among the different brittleness indexes of Sanshandao granite and the crack initiation stress: (a) $B_{1}$ and $\sigma_{\mathrm{ci}} ;(\mathrm{b}) B_{2}$ and $\sigma_{\mathrm{ci}} ;$ (c) $B_{3}$ and $\sigma_{\mathrm{ci}} ;$ (d) $B_{4}$ and $\sigma_{\mathrm{ci}}$.

\section{CONCLUSION}

In this paper, the existing brittleness indexes for rock were firstly reviewed and discussed. The brittleness indexes considering Class II post-peak behavior for rock were chosen. Triaxial compressive tests on the granite were carried out on the stiff testing machine with confining pressures 5, 10, 20, 30, 40, 50,60, 70, 80, 90, 100 and $110 \mathrm{MPa}$. The crack initiation stress, brittleness index, compressive strength, elastic modulus and Poisson's ratio were obtained from the experiments. Further, the effects of confining pressure o the mechanical behaviors of the granite were discussed. Finally, the relationships between the brittleness indexes and crack initiation stress were investigated and established. The following conclusions can be given as follows:

1. The stress-strain curves from the experiments show that the post-peak behavior of the granite is in Class I and Class II type. And under the effect of confining pressure, the granite behavior is mainly in Class II.

2. With the increasing of confining pressure, the crack initiation stress, compressive strength and elasticity modulus of the granite closely linearly increases.

3. A power function can describe the relationship between the brittleness index and crack initiation stress for Class I rock behavior while an exponential function can describe the brittleness index and crack initiation stress for Class II rock behavior. The brittleness indexes of $B_{1}, B_{2}, B_{3}$ and $B_{4}$ has been redefined as a function of crack initiation stress.

Although the experiments considered 12 different confining pressures from $5 \mathrm{MPa}$ to $110 \mathrm{MPa}$, the number of specimens is limited. More experiments should be carried out to verify and parameterize the relationship between the brittleness index and crack initiation stress in the future. 


\section{Acknowledgments}

This work was supported by Fundamental Research Funds for the Central Universities (No. FRF-TP-18-015A3) and National Key R\&D Program of China (No. 2018YFE0101100).

Author's Contribuitions: Conceptualization, X Xi and Q Guo; Methodology, X Xi and Q Guo; Investigation, $Y$ Zhang and J Pan; Formal analysis, $Y$ Zhang and J Pan; Writing - original draft, Xun Xi, Y Zhang; Writing - review \& editing, Xun Xi, $Y$ Zhang; Funding acquisition, Q Guo and M Cai; Resources, Q Guo and M Cai; Supervision, Q Guo and M Cai.

Editor: Pablo Andrés Muñoz Rojas.

\section{References}

Akinbinu, V.A (2016). Class I and Class II Rocks: Implication of Self-sustaining Fracturing in Brittle Compression. Geotechnical and Geological Engineering 34, 877-887.

Ashby M F, Sammis C G (1990) The damage mechanics of brittle solids in compression. Pure and Applied Geophysics 133(3):489-521.

Aubertin M,Gill D E,Simon R (1994) On the use of the brittleness index modified (BIM) to estimate the post peak behavior or rocks. Proceedings of the 1st North American Rock Mechanics Symposium. Austin: American Rock Mechanics Association $945-$ 952.

Baron L I. Determination of properties of rocks (1992) Gosgortekhizdat, Moscow 784-795.

Batougina I M, Petoukhov I M, Vinokur B S, Smirnov V A, Robata E N (1983) Methodological instructions for rockburst prophylaxis accounting the deposit geodynamics. Leningrad: VNIMI.

Bažant, Z. P. (1993). Scaling laws in mechanics of fracture. Journal of Engineering Mechanics, ASCE 119(9): 1828- 1844.

Bishop A W (1967) Progressive failure with special reference to the mechanism causing it. Proceedings of the Geotechnical Conference Oslo: 142-150.

Brace W F, Paulding B W, Scholz C H (1966) Dilatancy in the fracture of crystalline rocks. Journal of Geophysical Research 71(16): 3939-3953.

Cai M F, Brown E T (2017) Challenges in the mining and utilization of deep mineral resources. Engineering 3(4): $432-433$.

Cai M, Kaiser P K, Tasaka Y, et al (2004) Generalized crack initiation and crack damage stress thresholds of brittle rock masses near underground excavations. International Journal of Rock Mechanics and Mining Sciences 41(5): 833-847.

Chen G, Zhao C, Wei T, Wang J (2018). Evaluation method of brittle characteristics of rock based on full stress-strain curve and crack initiation stress. Chinese Journal of Rock Mechanics and Engineering 37(1): 51-59.

Coates D.F., Parsons R.C. (1966) Experimental criteria for classification of rock substances. International Journal of Rock Mechanics and Mining Sciences \& Geomechanics Abstracts 3(3): 181-189,

Damjanac B, Fairhurst C (2010) Evidence for a Long-Term Strength Threshold in Crystalline Rock. Rock Mechanics and Rock Engineering 43(5): 513-531.

Diederichs M S, Kaiser P K, Eberhardt E (2004) Damage initiation and propagation in hard rock during tunnelling and the influence of near-face stress rotation. International Journal of Rock Mechanics and Mining Sciences 41(5): 785-812.

Guo, Q.; Pan, J.; Cai, M.; Zhang, Y (2020) Analysis of Progressive Failure Mechanism of Rock Slope with Locked Section Based on Energy Theory. Energies 13, 1128.

Hajiabdolmajid V, Kaiser P K (2003) Brittleness of rock and stability assessment in hard rock tunneling. Tunnelling and Underground Space Technology 18(1): 35-48.

Hajiabdolmajid V, Kaiser P K, Martin C D (2002) Modelling brittle failure of rock. International Journal of Rock Mechanics and Mining Sciences 39(6): 731-741. 
Huang D., Li X. (2017) Numerical simulation research on characteristic strength of marble based on development of microcrack. Rock and Soil Mechanics 38(1): 253-262.

Hucka V., Das B. (1974) Brittleness determination of rocks by different methods. International Journal of Rock Mechanics and Mining Sciences \& Geomechanics Abstracts 11(10): 389-392.

Jiang, J., Wang, D., Han, X., Di, S (2020) Relationship between Brittleness Index and Crack Initiation Stress Ratio for Different Rock Types. Advances in Civil Engineering 2020: 8091895

Lajtai E Z (1974) Brittle fracture in compression. International Journal of Fracture Mechanics 10(4): 525-536.

Li Q, Chen M, Jin Y et al (2012) Indoor evaluation method for shale brittleness and improvement. Chinese Journal of Rock Mechanics and Engineering 31(8): 1681-1685.

Martin C D, Chandler N A (1994) The progressive fracture of Lac du Bonnet granite. International Journal of Rock Mechanics and Mining Science and Geomechanics Abstracts 31(6):643-659.

Mews, K.S.; Alhubail, M.M.; Barati, R.G (2019) A Review of Brittleness Index Correlations for Unconventional Tight and UltraTight Reservoirs. Geosciences 9(7), 319.

Nicksiar M, Martin C D (2012) Evaluation of methods for determining crack initiation in compression tests on low-porosity rocks. Rock Mechanics and Rock Engineering 45(4): 607-617.

Rybacki E, Meier T, Dresen G (2016) What controls the mechanical properties of shale rocks? - Part II: Brittleness.Journal of Petroleum Science and Engineering 144: 39-58.

Sih, G.C. (1974) Strain-energy-density factor applied to mixed mode crack problems. International Journal of Fracture 10(3): 305-321.

Stavrogin A N, Protossenia A G (1985) Rock strength and excavation stability in great depth. Moscow: Nedra.

Tarasov B, Potvin Y (2013) Universal criteria for rock brittleness estimation under triaxial compression. International Journal of Rock Mechanics and Mining Sciences 59(4): 57-69.

Wawersik W R, Fairhurst C (1970) A study of brittle rock fracture in laboratory compression experiments. International Journal of Rock Mechanics and Mining Sciences \& Geomechanics Abstracts 7(5): 561-575.

Xi X, Wu X, Guo Q, and Cai M (2020) Experimental Investigation and Numerical Simulation on the Crack Initiation and Propagation of Rock with Pre-Existing Cracks. IEEE Access, 8: 129636-129644.

Xi X, Yang S, Li C Q (2018b) A non-uniform corrosion model and meso-scale fracture modelling of concrete. Cement and Concrete Research 108(6): 87-102.

Xi X, Yang S, Li CQ, Cai M, Hu X, Shipton Z K (2018a) Meso-scale mixed-mode fracture modelling of reinforced concrete structures subjected to non-uniform corrosion. Engineering Fracture Mechanics 199: 114-30.

Xia Y, Li L, Tang C A et al (2016) Rock brittleness evaluation based on stress dropping rate after peak stress and energy ratio. Chinese Journal of Rock Mechanics and Engineering 35(6): 1141-1154.

Xu, X., Wu, S.; Jin, A.; Gao, Y (2018) Review of the Relationships between Crack Initiation Stress, Mode I Fracture Toughness and Tensile Strength of Geo-Materials. International Journal of Geomechanics 18(10): 04018136.

Zhao X G, Wang J, Ma L K, et al (2013) Acoustic emission behaviors of the Beishan granite under uniaxial and triaxial compression conditions. Proceedings of the 3rd ISRM SINOROCK Symposium. London: CRC Press, Balkema. 